\title{
KOMPOSISI JENIS DAN KEANEKARAGAMAN FITOPLANKTON SAAT PENAMBANGAN PASIR INTENSIF DI MUARA SUNGAI POHARA SULAWESI TENGGARA
}

Species composition and diversity of phytoplankton during sand mining season in Pohara estuary, Southeast Sulawesi

(Bahtiar ${ }^{1}$ dan N. Irawati $^{1}$ )

${ }^{1}$ Fakultas Perikanan dan Ilmu Kelautan Universitas Halu Oleo

E-mail : tiar_77unhalu@yahoo.com

\begin{abstract}
Local communities along the banks of Pohara River have been benefited from the ecological services provided by the river ecosystem. However, the increasing trend of extraction pattern of natural resources through several economic activities along the river has put significant pressure on the surrounding ecosystem. One of the activities that allegedly have an impact on the estuary productivity decline of the area is intensive sand mining operations. This recent study was carried out to study the composition and diversity of phytoplankton during heavy sand mining season in order to provide baseline data for the better management of the area. Field work was conducted from April 2007 to February 2008 in Pohara estuary. Plankton samples were collected from six sampling stations and analyzed using quantitative descriptive method. Results of the study found that the highest spatial and temporal distribution of phytoplankton species found in the areas were phytoplankton from the classes of Chlorophyceae and Dinophyceae while the lowest was from the class of Euglenophyceae. Two species found in every sampling station were Euglenophyceae and Cyanophyceae. Diversity index showed significant differences and categorized from high to low diversity based on sampling stations and observation times with the values ranged between 2231-2524 and 0906-2346, respectively. In addition, the uniformity index based on station and observation times ranged between 0758-0819 and 0906-2346, respectively which fell in the category of high and medium uniformity.
\end{abstract}

Keywords : Phytoplankton, Composition, Diversity, Pohara River 


\section{Pendahuluan}

Ungai Pohara merupakan salah satu - sungai dengan tipe dendritik dan $\bigcirc$ permanen. Sungai ini membentang di sepanjang jazirah tenggara Sulawesi yang melewati 3 kabupaten yang berhulu di Kabupaten Kolaka Utara dan Konawe, Selanjutnya sebagian anak sungai ini melintasi Taman Nasional Rawa Aopa (TNRW) Kabupaten Konawe Selatan (Muara Aopa) dan bermuara di Kabupaten Konawe. Oleh karena itu, ketersediaan unsur hara dalam menunjang proses fotosintesis cukup memadai karena tingginya masukan dari TNRW berupa nitrogen dan fosfat di perairan (Bahtiar, 2012).

Sungai Pohara dimanfaatkan masyarakat dalam berbagai peruntukkan diantaranya kebutuhan rumah tangga (MCK), pertanian lahan basah (sawah), perkebunan, transportasi air, perikanan dan penambangan pasir. Kegiatan penambangan pasir telah lama dilakukan oleh masyarakat di daerah aliran sungai, terutama di sepanjang zona muara Sungai Pohara. Kegiatan penambangan ini terjadi secara parsial dibeberapa bagian sungai sepanjang $17 \mathrm{~km}$ (Bahtiar, 2005). Penambangan pasir yang dilakukan tidak terbatas hanya dengan menggunakan alat tradisional (keranjang dan perahu), namun dilakukan dengan menggunakan mesin pengisap pasir. Tingginya aktivitas ini diduga berdampak pada tingginya kekeruhan perairan di sepanjang muara sungai ini (Bahtiar, 2007).
Kondisi ini dapat menurunkan komposisi keanekaragaman jenis fitoplankton perairan (produktivitas primer) karena proses fotosintesis hanya terjadi di lapisan atas saja $(40 \mathrm{~cm})$. Pada sisi lain, informasi yang berhubungan dengan produktivitas perairan belum diketahui, sehingga perlu dilakukan penelitian komposisi keanekaragaman jenis fitoplankton perairan.

Penelitian ini bertujuan untuk mengetahui kelimpahan dan keanekaragaman fitoplankton saat penambangan pasir intensif. Hasil penelitian ini diharapkan dapat memberikan gambaran kepada pemerintah daerah sehingga dapat dijadikan bahan informasi dalam pengelolaan yang berhubungan dengan Daerah Aliran Sungai Konawe.

\section{Metode}

\section{Waktu dan Lokasi Penelitian}

Penelitian ini dilakukan di Perairan Sungai Pohara (segmen muara) Kabupaten Konawe Sulawesi Tenggara. Lokasi penelitian dibagi menjadi 6 stasiun berdasarkan karakter segmen perairan yaitu atas, tengah dan akhir muara. Setiap 2 stasiun mewakili 1 segmen perairan. Pengamatan dilakukan setiap bulan selama 11 bulan secara berkala (time series) dimulai dari bulan April 2007-Februari 2008. Sampel plankton dianalisis di laboratorium Fakultas Perikanan dan Ilmu Kelautan Unhalu (Gambar 1). 

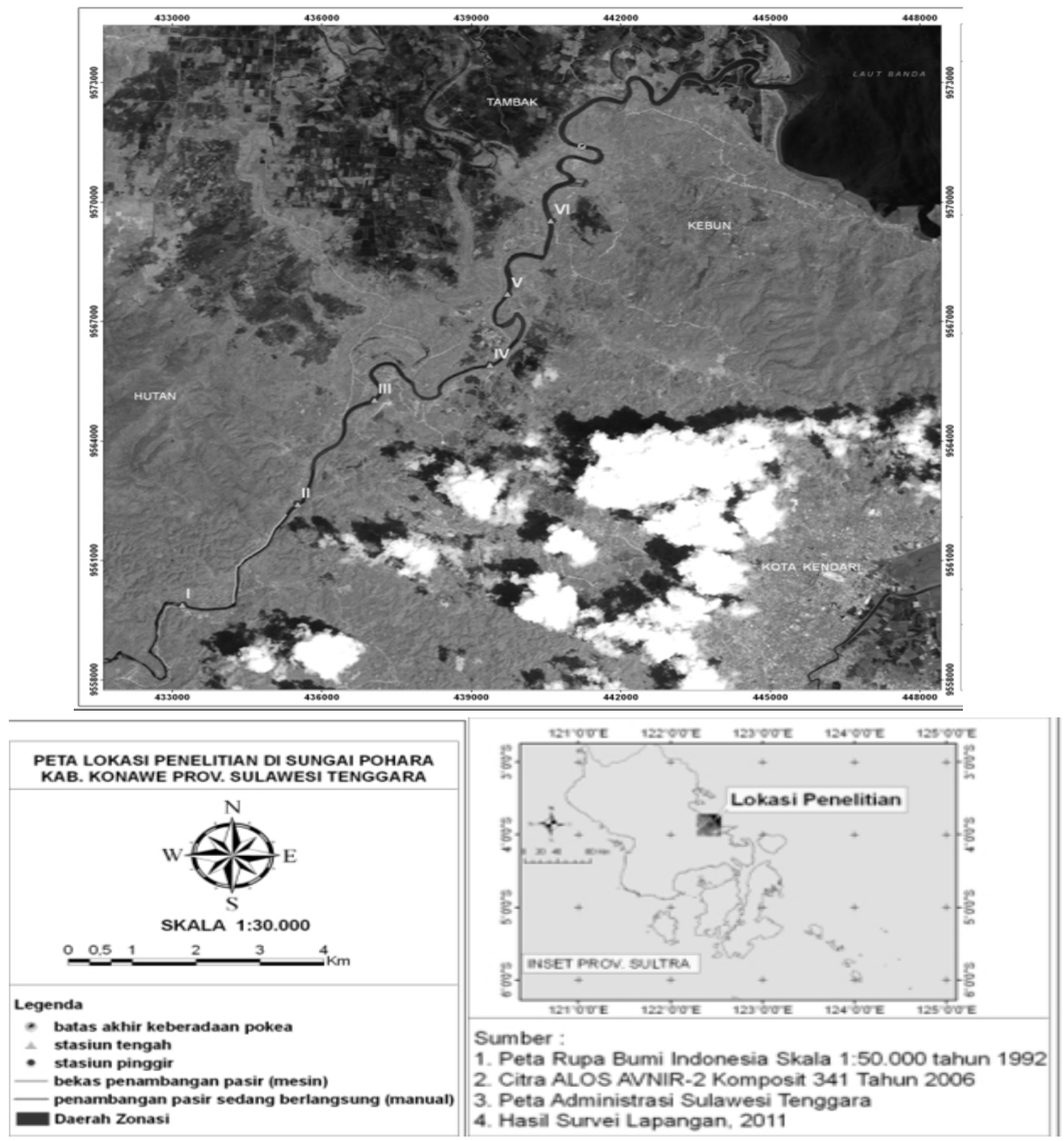

Gambar 1. Peta lokasi penelitian di Sungai Pohara

\section{Sampling dan Analisis Laboratorium}

Pengambilan sampel kualitas air dan sampel plankton diambil secara horizontal di bawah permukaan air. Untuk sampel plankton diambil sebanyak 50 liter air dengan menggunakan plankton net yang berukuran jaring $30 \mu \mathrm{m}$ dan dipadatkan kedalam $20 \mathrm{ml}$ botol sampel plankton. Kemudian dimasukan ke dalam botol sampel yang berlabel dan ditetesi dengan pengawet lugol 1\% sebanyak 3-4 tetes. Selanjutnya dilakukan pengidentifikasian dan menghitung kelimpahan jenis plankton di laboratorium perikanan dengan cara mengambil sampel air sebanyak $0.1 \mathrm{ml}$ menggunakan pipet, kemudian diletakan di atas gelas objek dan diamati dengan menggunakan mikroskop binokuler. Pemeriksaan dilakukan sebanyak dua ulangan dan setiap ulangan dilakukan 3 lapang pandang. Identifikasi plankton menggunakan buku petunjuk Mizuno (1993), dan Edmonson (1963). 


\section{Analisis Data}

Penghitungan kelimpahan plankton menggunakan formula APHA (2005) dengan metode mikrotransek yaitu :

$$
N=\frac{O i}{O p} \times \frac{V r}{V o} \times \frac{1}{V s} \times \frac{n}{p}
$$

Keterangan : $N=$ jumlah total individu/liter, $O_{i}=$ luas gelas penutup $\left(\mathrm{mm}^{2}\right), O p=$ luas satu lapang pandang $\left(\mathrm{mm}^{2}\right), V_{0}=$ volume satu tetes air contoh $(\mathrm{ml}), V r=$ volume air yang tersaring dalam jaring bucket, $V_{S}=$ volume yang tersaring oleh jaring plankton, $n$ $=$ jumlah plankton pada seluruh lapang pandang, dan $P=$ jumlah lapang pandang. Komposisi jenis fitoplankton dianalisis secara semi kuantitatif (persentase), Keanekaragaman jenis fitoplankton dihitung dengan menggunakan indeks ShannonWiener. Keterkaitan kelimpahan fitoplankton dan kualitas air menggunakan analisis korespondes (CA).
Hasil

Komposisi Jenis Fitoplankton

Komposisi jenis fitoplankton terbanyak ditemukan pada kelas Chlorophyceae (43\%), disusul oleh kelas Dinophyceae (21\%). Komposisi jenis terendah ditemukan pada kelas Tintinidae dan Euglenophyceae (3\%) (Gambar 2).

\section{Kelimpahan Fitoplankton}

Kelimpahan fitoplankton berkisar 1321-2268 ind/1. Kelimpahan fitoplankton relatif sama di setiap stasiun kecuali di stasiun VI yang lebih rendah dibandingkan stasiun lainnya. Kelimpahan jenis tertinggi di setiap stasiun didominasi oleh 2 kelas yaitu kelas Dinophyceae dan Chlorophyceae. Kelimpahan terendah ditemukan pada 2 kelas yaitu Cyanophyceae dan Bacillariophyceae. Secara umum, jenis-jenis fitoplankton tidak memperlihatkan perbedaan kelimpahan fitoplankton di setiap stasiun (Gambar 3).

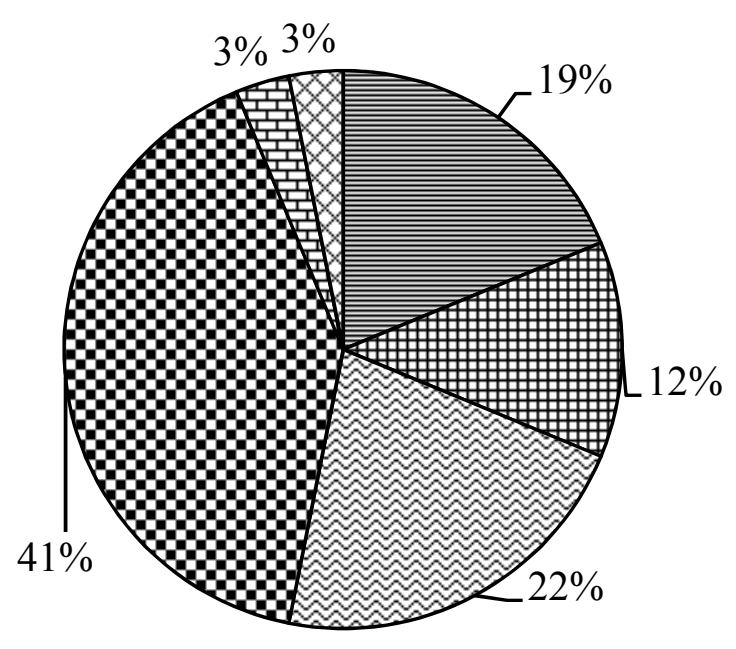

Gambar 2. Komposisi jenis fitoplankton pasca penambangan pasir intensif
目Kelas Bacillarophyceae

$\boxplus$ Kelas Cyanophyceae

图Kelas Dinophyceae

$\mathbf{\square}$ Kelas Chlorophyceae

巴Kelas Euglenophyceae

$\square$ Kelas Tintinidae 


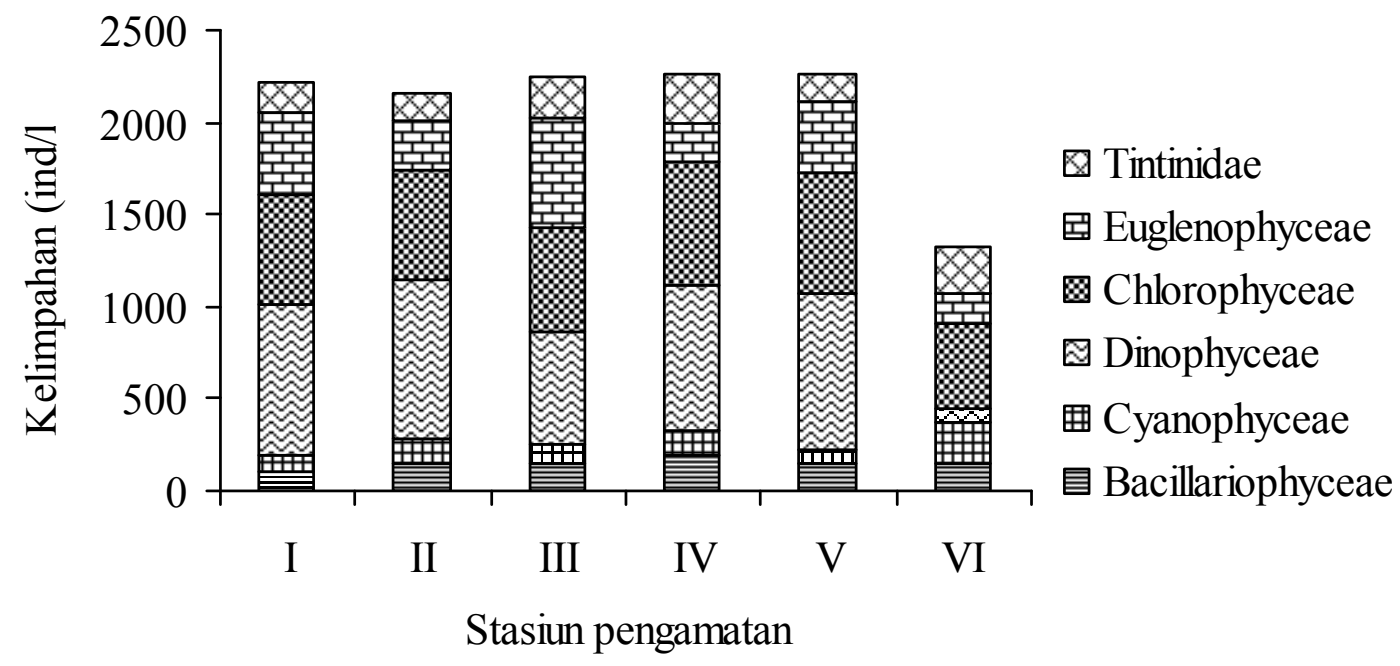

Gambar 3. Kelimpahan fitoplankton di setiap stasiun pasca penambangan pasir intensif

Kelimpahan fitoplankton yang ditemukan dari bulan April 2007-Februari 2008 berkisar 156-2879 ind/l. Kelimpahan fitoplankton ditemukan bervariasi yang ditemukan cenderung meningkat dan mencapai puncak dengan kelimpahan tertinggi pada bulan Juli dan terus mengalami penurunan sampai pada akhir penelitian di bulan Februari. Komposisi jenis yang dominan di setiap bulannya ditemukan lebih bervariasi. Jenis yang dominan ditemukan adalah Dinophyceae (Juli, Agustus dan Januari), Chlorophyceae (Mei, Juni, September dan Oktober) dan Euglenophyceae (April). Namun, Dinophyceae dan Chlorophyceae tidak ditemukan di setiap bulannya. Beberapa jenis yang kelimpahannya lebih rendah seperti Euglenophyceae dan Cyanophyceae ditemukan disetiap pengamatan (Gambar 4).

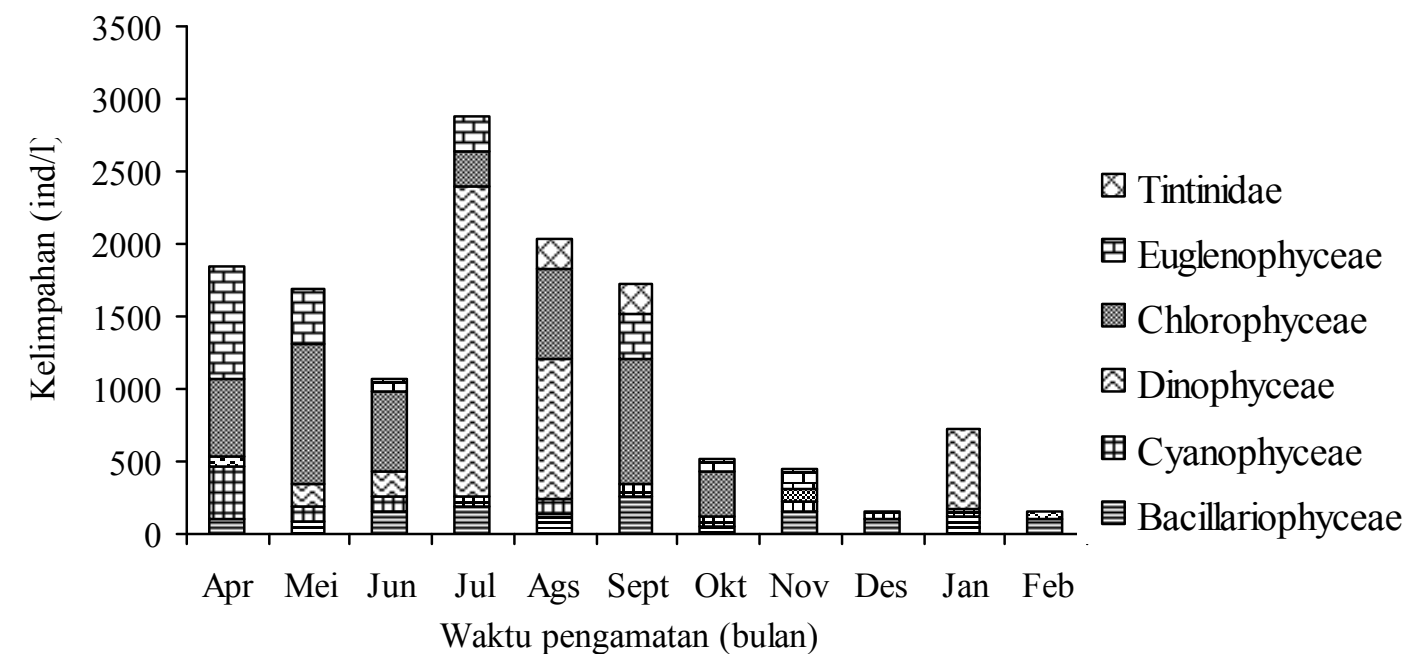

Gambar 4. Kelimpahan jenis fitoplankton pasca penambangan pasir intensif berdasarkan waktu pengamatan

perbedaan yang berada pada kisaran 2.231-

Keanekaragaman dan Keseragaman Jenis Fitoplankton

Indeks keanekaragaman fitoplankton di setiap stasiun relatif tidak menunjukkan
2.524. Nilai ini berada pada kategori kisaran keanekaragaman sedang. Demikian halnya dengan indeks kesamaan yang berada pada 
kisaran 0.758-0.819 dengan kategori (Tabel 3).

kesamaan jenis tinggi di setiap stasiunnya

Tabel 3. Indeks keanekaragaman dan keseragaman jenis fitoplankton di Sungai Pohara berdasarkan stasiun penelitian

\begin{tabular}{ccccc}
\hline Stasiun & Keanekaragaman & Keseragaman & Jumlah spesies & \\
I & 2.331 & 0.792 & 19 & \\
II & 2.454 & 0.819 & 20 & \\
III & 2.374 & 0.793 & 20 & \\
IV & 2.231 & 0.758 & 19 & \\
V & 2.342 & 0.81 & 18 & \\
VI & 2.524 & 0.817 & 22 & kategori \\
Berbeda & halnya & dengan & keanekaragaman rendah. & Keseragaman \\
keanekaragaman & fitoplankton berdasarkan & fitoplankton berada pada kisaran 0.618-0.914 \\
waktu pengamatan yang berkisar & $0.906-$ & yang berada pada kategori keseragaman \\
2.346. Namun secara umum, nilai & sedang sampai tinggi (Tabel 4). &
\end{tabular}

keanekaragaman cenderung berada pada nilai

Tabel 4. Indeks keanekaragaman dan keseragaman jenis fitoplankton di Sungai Pohara berdasarkan stasiun penelitian

\begin{tabular}{lccc}
\hline Bulan & Keanekaragaman & Keseragaman & Jumlah Spesies \\
\hline April & 1.962 & 0.765 & 13 \\
Mei & 1.772 & 0.739 & 11 \\
Juni & 2.346 & 0.846 & 16 \\
Juli & 1.673 & 0.618 & 15 \\
Agustus & 1.762 & 0.735 & 11 \\
September & 1.758 & 0.764 & 10 \\
Oktober & 1.783 & 0.857 & 8 \\
November & 1.905 & 0.916 & 8 \\
Desember & 1.47 & 0.914 & 5 \\
Januari & 0.906 & 0.653 & 4 \\
Februari & 0.986 & 0.898 & 3 \\
\hline
\end{tabular}

\section{Kualitas Perairan}

Nilai kualitas perairan berdasarkan stasiun dan waktu penelitian disajikan pada Tabel 5 dan Tabel 6.

Tabel 5. Kondisi kualitas perairan pasca penambangan pasir intensif berdasarkan stasiun penelitian

\begin{tabular}{cccccccccccccc}
\hline & \multicolumn{10}{c}{ Parameter Fisika-Kimia Perairan } \\
\cline { 2 - 14 } stasiun & Sh & ars & $\mathrm{pH}$ & Kcr & kdl & DO & BOD & Fo & Nit & TSS & TDS & Ca \\
\hline I & 28,44 & 1,32 & 6,54 & 32,18 & 5,58 & 6,48 & 4,50 & 2,11 & 2,61 & 381,45 & 87,00 & 0,85 \\
II & 28,16 & 1,20 & 6,54 & 31,36 & 4,67 & 6,35 & 3,99 & 1,88 & 2,49 & 318,27 & 86,73 & 0,69 \\
III & 28,21 & 0,95 & 6,53 & 28,82 & 4,27 & 5,95 & 3,99 & 1,98 & 3,35 & 366,73 & 84,36 & 0,82 \\
IV & 28,46 & 1,02 & 6,55 & 32,73 & 4,75 & 5,33 & 3,78 & 2,20 & 3,31 & 366,73 & 83,27 & 0,81
\end{tabular}


Komposisi Jenis dan Keanekaragaman

\begin{tabular}{ccccccccccccc}
$\mathrm{V}$ & 27,99 & 1,08 & 6,57 & 31,45 & 5,05 & 6,59 & 4,16 & 1,27 & 3,56 & 331,64 & 86,82 & 0,85 \\
$\mathrm{VI}$ & 28,54 & 0,99 & 6,57 & 30,27 & 2,75 & 6,15 & 4,00 & 1,29 & 3,95 & 254,27 & 86,36 & 0,87 \\
\hline
\end{tabular}

Tabel 6. Kondisi kualitas perairan pasca penambangan pasir intensif berdasarkan waktu pengamatan

\begin{tabular}{cccccccccccccc}
\hline \multirow{2}{*}{ Bulan } & \multicolumn{10}{c}{ Parameter Fisika-Kimia Perairan } \\
\cline { 2 - 14 } & Sh & ars & pH & kcr & kdl & DO & BOD & Fo & Nit & TSS & TDS & Ca \\
\hline Apr & 27,17 & 1,16 & 6,37 & 21,33 & 5,03 & 5,80 & 1,42 & 6,32 & 7,10 & 442,50 & 81,33 & 1,09 \\
Mei & 26,50 & 1,36 & 6,55 & 26,00 & 5,10 & 5,48 & 2,80 & 3,05 & 6,43 & 481,00 & 83,50 & 1,08 \\
Jun & 27,08 & 1,88 & 6,52 & 26,83 & 5,18 & 4,80 & 3,93 & 3,93 & 2,08 & 502,67 & 100,00 & 1,04 \\
Jul & 26,82 & 1,21 & 6,47 & 28,00 & 5,25 & 7,20 & 3,82 & 2,48 & 3,68 & 364,67 & 76,83 & 1,12 \\
Ags & 26,77 & 2,61 & 6,52 & 35,83 & 5,25 & 8,22 & 5,52 & 0,82 & 2,32 & 240,17 & 69,00 & 0,87 \\
Sep & 26,70 & 1,88 & 6,52 & 21,33 & 4,75 & 9,68 & 7,33 & 0,40 & 1,32 & 253,50 & 74,83 & 0,49 \\
Okt & 29,92 & 0,49 & 6,67 & 35,17 & 3,67 & 5,22 & 3,50 & 0,59 & 1,48 & 253,67 & 81,67 & 0,60 \\
Nov & 30,85 & 0,57 & 6,70 & 42,67 & 4,33 & 4,70 & 3,68 & 0,32 & 1,43 & 302,50 & 97,33 & 0,55 \\
Des & 28,23 & 0,50 & 6,50 & 31,50 & 3,92 & 5,58 & 4,57 & 0,72 & 3,20 & 280,17 & 92,33 & 0,78 \\
Jan & 31,23 & 0,21 & 6,61 & 35,67 & 3,67 & 5,87 & 4,27 & 0,61 & 4,35 & 321,17 & 95,67 & 0,77 \\
Feb & 30,03 & 0,19 & 6,65 & 38,17 & 3,50 & 5,02 & 3,95 & 0,43 & 1,93 & 259,67 & 90,83 & 0,58 \\
\hline
\end{tabular}

\section{Hubungan Kelimpahan Jenis Fitoplankton dan Kualitas Perairan}

Kualitas air yang menjadi penciri di stasiun III dan IV adalah TSS, sedangkan jenis fitoplankton penciri distasiun masing-masing adalah kelas Euglenophyceae dan Tintinidae. Kualitas air dan jenis fitoplankton yang berperan di stasiun II dan VI masing-masing adalah kecepatan arus dan Cyanophyceae, sedangkan kualitas air dan jenis fitoplankton di stasiun $\mathrm{V}$ masing-masing adalah nitrat dan kedalaman perairan (Gambar 5).

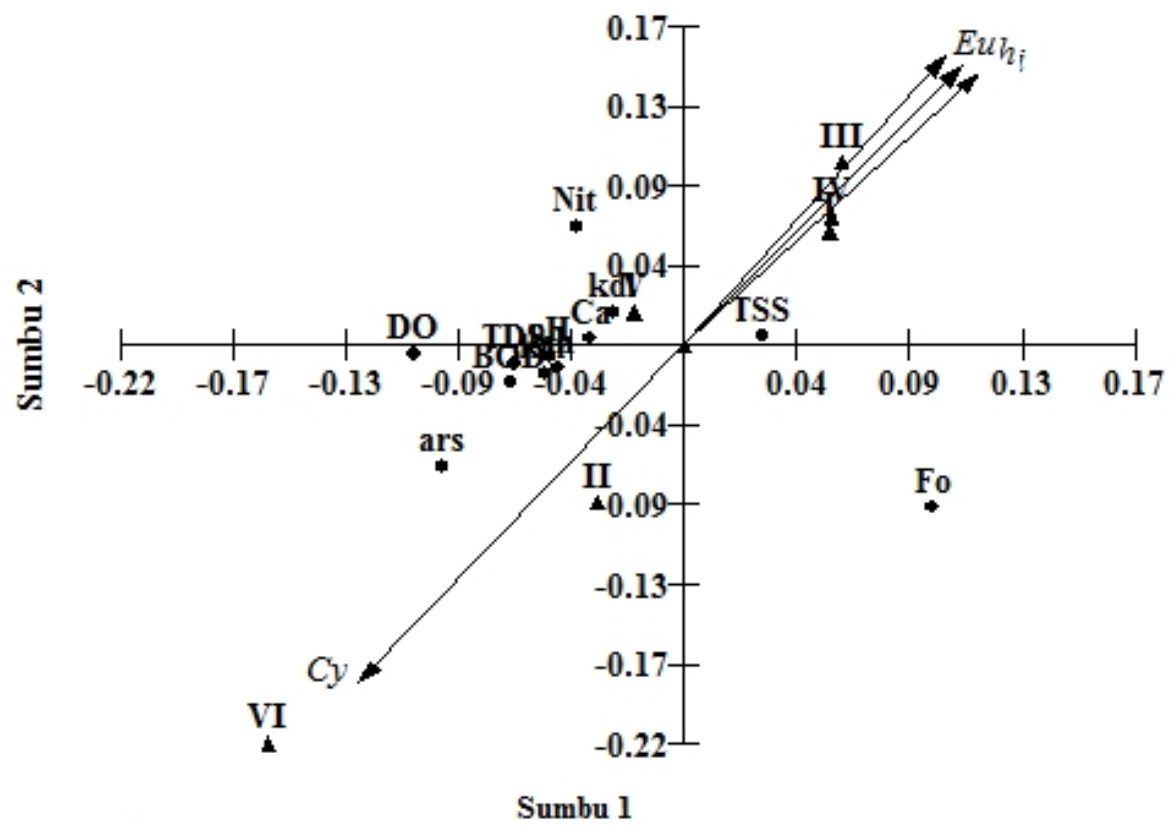

Gambar 5. Hubungan kelimpahan jenis fitoplankton dan kualitas perairan berdasarkan stasiun pengamatan 
Nitrat dan fosfat menjadi menjadi penciri kualitas air di bulan Juli yang ditunjukkan dengan dominansi kelas Dinophyceae, dan beberapa jenis lainnya di kelas Bacillariophyceae. Kelas Euglenaophyceae,Chlorophyceae dan

ophy

ceae

menj

adi

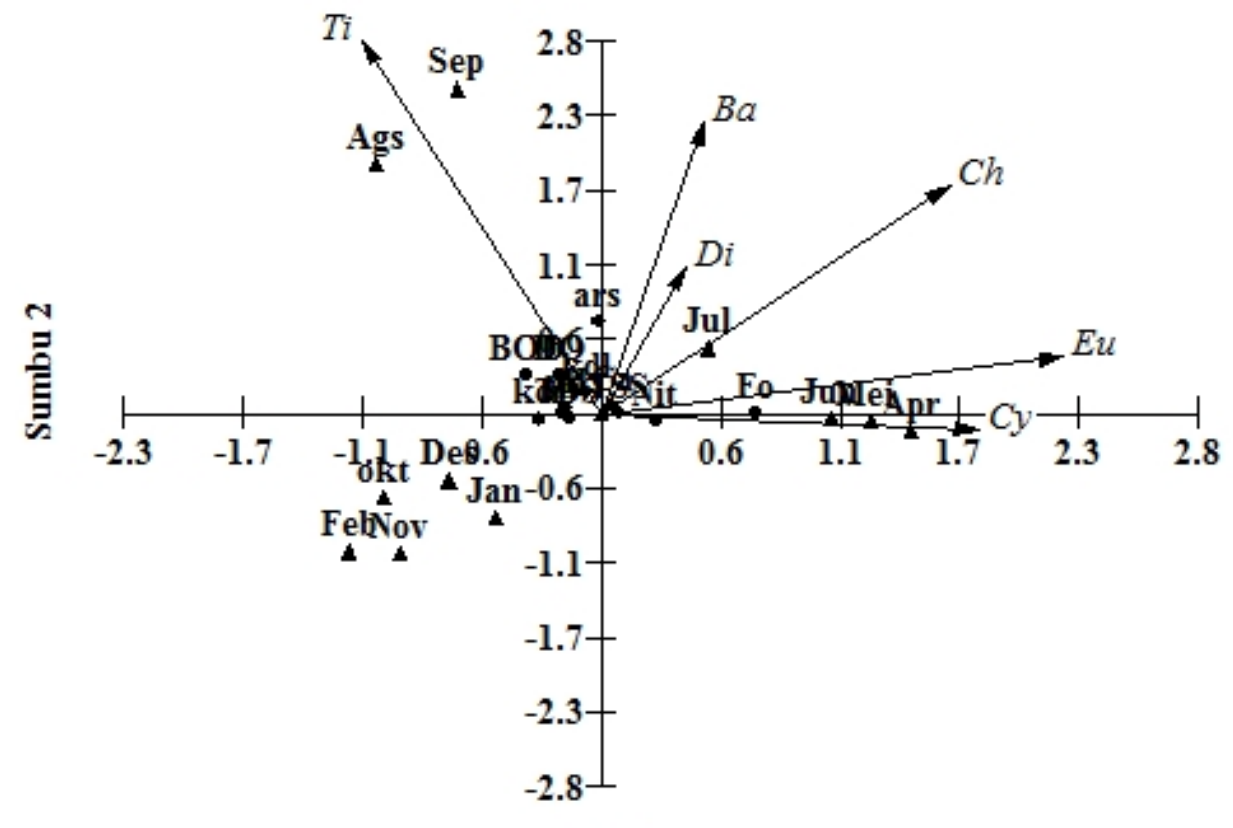

Sumbu 1

Gambar 6. Hubungan kelimpahan jenis fitoplankton dan kualitas perairan berdasarkan waktu pengamatan

\section{Pembahasan}

Komposisi jenis plankton terbanyak ditemukan pada kelas Chlorophyceae sebanyak 13 jenis. Jenis-jenis fitoplankton tersebut adalah : Closterium sp., Pediastrum $\mathrm{sp}$, Pleurotaenium sp, Coelastrum sp, Ankistrodesmus sp., Crisopsis sp., Closterium sp., Astasia sp., Heteronema sp., Isochrysis sp., Platyias sp., Pleuronema sp., Colothrix sp., Arcella sp. Selanjutnya pada kelas Dinophyceae terdiri dari 7 jenis dengan jenis-jenis yang ditemukan adalah : Cyanidium sp., Difflugia sp., Gymnodinium sp., Gyrodinium sp., Peredinium sp., Menoidium sp., dan Eutreptia sp. Pada kelas Bacillariopyceae terdiri dari 6 jenis yang terdiri atas : Bacillaria sp., Melosira sp., Navicula sp., Nitzschia sp., Synedra sp., dan Gyrosigma sp. Kelas Cyanophyceae terdiri penciri di bulan April, Mei, dan Juni (Gambar 6). 
dominan di perairan sungai. Seperti yang dinyatakan oleh Ruttner (1965) dan Boney (1975) bahwa di perairan tawar, fitoplankton yang dominan dan mempunyai penyebaran yang luas serta memegang peranan penting dalam rantai makanan adalah Bacillariophyceae, Cyanophyceae dan Chlorophyceae. Opute (2000) dalam Akohoma (2008) juga mengemukakan umumnya kelas Chlorophyceae kurang toleran terhadap salinitas dan hanya terbatas pada perairan tawar.

Kelimpahan plankton yang ditemukan di perairan Sungai Pohara tergolong rendah. Hal ini berhubungan dengan tingginya nilai TSS pada seluruh stasiun penelitian (Tabel 5 dan 6). Tingginya nilai TSS berhubungan dengan penetrasi cahaya matahari ke dalam perairan. Sehingga keberadaan nilai TSS yang tinggi akan mengurangi penetrasi cahaya matahari yang masuk ke dalam perairan sehingga mengganggu proses fotosintesis fitoplankton. Hal ini didukung oleh Kimmel dan Groeger (1984), Reynolds (1988) dan Thornton et al. (1990) komunitas fitoplankton tidak hanya dipengaruhi oleh grazzing zooplankton, tetapi juga oleh ketersediaan nutrien dan cahaya yang cukup. Sejalan dengan Steinhart et. al (2002) dan Palleyi et al. (2011) bahwa kekeruhan berkorelasi negatif dengan fitoplankton di perairan. Rendahnya kelimpahan fitoplankton juga dipengaruhi oleh kondisi perairan sungai yang memiliki arus yang deras, sehingga fitoplankton tidak sempat untuk tinggal di kolom air, hal ini seperti yang dinyatakan oleh Odum (1988) dan Abel (1989) perairan yang relatif tenang merupakan habitat yang cocok untuk fitoplankton.

Kelimpahan fitoplankton relatif sama disetiap lokasi penelitian kecuali di stasiun VI yang letaknya lebih dekat dengan muara sehingga terkena limpasan air laut. Hal ini disebabkan oleh tipe perairan sungai yang mengalir sehingga fitoplankton didistribusikan merata di sepanjang aliran sungai. Kelimpahan fitoplankton yang rendah di stasiun VI disebabkan oleh adanya perubahan kualitas air terutama peningkatan salinitas sehingga fitoplankton yang adaptif pada kondisi tersebut yang dapat bertahan hidup. Seperti yang dinyatakan oleh Flameling \& Kromkamp (1994), Bisson \& Kirst (1995) \& Lionard et al. (2005) bahwa pada suksesi fitoplankton yang didasarkan atas perubahan salinitas di sungai dan daerah pasang surut, dijumpai spesies fitoplankton stenohaline dan akan mengalami stres secara osmotik jika terpapar dengan perubahan salinitas.

Kelimpahan fitoplankton cenderung meningkat dan mencapai puncak di bulan Juli dan terus mengalami penurunan sampai pada akhir penelitian di bulan Februari. Hal ini disebabkan oleh dinamika beberapa parameter kualitas air yang mengikuti pola kelimpahan temporal kelimpahan fitoplankton seperti nitrat dan fosfat. Nitrat perairan memperlihatkan nilai yang relatif sama sampai bulan Juli dan terus mengalami penurunan di bulan Agustus-November walaupun ada peningkatan diakhir penelitian, sedangkan Fosfat perairan mengalami peningkatan di awal penelitian dan terus mengalami penurunan di akhir penelitian. Suplai nitrat dan fosfat berasal dari Rawa Aopa yang masuk ke sungai karena peningkatan debit air sungai dari tingginya curah hujan di bulan tersebut. Seperti yang ditemukan pada penelitian Chessman (1985), Domitrovic et al. (2007) dan Ozbay (2011) bahwa rendahnya konsentrasi fitoplankton diikuti dengan rendahnya konsentrasi nutrien $\mathrm{N}$ dan $\mathrm{P}$ di perairan sungai. Selain itu perubahan komposisi komunitas fitoplankton dipengaruhi oleh peningkatan frekuensi dan kuantitas dari masukan nutrien di perairan (Piehler et al. 2004).

\section{Kesimpulan}

Komposisi jenis fitoplankton yang ditemukan tertinggi di Muara Sungai Pohara Sulawesi Tenggara Saat penambangan pasir intensif pada kelas Chlorophyceae dan Dinophyceae sedangkan komposisi terendah 
pada kelas Euglenophyceae. Beberapa jenis yang ditemukan disetiap pengamatan adalah Euglenophyceae dan Cyanophyceae. Indeks keanekaragaman menunjukkan perbedaan berdasarkan stasiun dan waktu pengamatan yang nilai kisaran masing-masing 2.231-2.524 dan 0.906-2.346, dengan kategori keanekaragaman tinggi dan rendah. Demikian halnya dengan indeks keseragaman berdasarkan stasiun dan waktu pengamatan yang menunjukkan nilai kisaran masing-masing yaitu 0.758-0.819 dan 0.9062.346 yang umumnya berada pada kategori keseragaman tinggi dan sedang.

Kelimpahan fitoplankton yang diperoleh berdasarkan stasiun berkisar 13212268 ind/1 dan 156-2879 ind/l berdasarkan waktu penelitian. Kelimpahan fitoplankton cenderung meningkat dan mencapai puncak di bulan Juli dan terus mengalami penurunan sampai pada akhir penelitian di bulan Februari.

\section{DAFTAR PUSTAKA}

Abel, P.D. 1989. Water Pollution Biology. London: Ellis Horwood.

Akoma, O.C. 2008. Phytoplankton and nutrient dynamics of a tropical estuarine system, Imo River Estuary, Nigeria. African Research Review. 2(2): 253-264.

APHA (American Public Health Association), 2005. Standard Methods for the Examination of Water and Wastewater. $21^{\text {Th }}$ Edition. APHA. AWWA (American Water Works Association) and WPCF (Water Pollution Control Federation). Washington.

Bahtiar. 2007. Preperensi Habitat dan Lingkungan Perairan Pokea (Batissa violacea var. celebensis. von Martens, 1897) di Sungai Pohara Sulawesi Tenggara. Jurnal Aqua Hayati. Volume 5: 81-87.
Bahtiar, 2012. Studi Bioekologi dan Dinamika Populasi Pokea Pokea (Batissa violacea var. celebensis. von Martens, 1897) yang Tereksploitasi Sebagai Dasar Pengelolaan di Sungai Pohara Sulawesi Tenggara. Disertasi. IPB.

Bisson, M. A. \& G. O. Kirst, 1995. Osmotic acclimation and turgor pressure regulation in algae. Naturwissenschaften. 82:461-471.

Boney, C.A.D. 1975. Phytoplankton. $1^{\text {st }}$ Ed. The Camelot Press Ltd. Soutampton. 97p.

Chessman, B. C. (1985). Phytoplankton of the La Trobe River, Victoria. Australian Journal of Marine and Freshwater Research 36: 115-122.

Domitrovic, Z.Y., A. S. G. Neiff \& S.L. Casco (2007). Abundance and diversity of phytoplankton in the Parana River (Argentina) $220 \mathrm{~km}$ downstream of the Yacyreta reservoir. Brazilian Journal of Biology 67: 53-63.

Edmonson, W.T. 1963. Freshwater Biology. Second Edition. John Wiley and Sons, Inc., New York. 1248 p.

Flameling, I. A. \& J. Kromkamp, 1994. Responses of respiration and photosynthesis of Scenedesmus protuberans Fritsch to gradual and steep salinity increases. Journal of Plankton Research. 16: 1781-1791.

George, E.E., Samuel I.U., Andem A.B. 2012. Composition and Abundance of Phytoplankton of Adiabo River in Calabar River system, Southeast, Nigeria. European Journal of Zoological Research. 1 (4):93-98.

Kimmel, B.L. \& O.W. Groeger. 1984. Factors Controlling Phytoplankton Production in Lakes Reservoir : A Perspective. EPA. Washington DC. 227-281p.

Lionard, M, K. Muylaert, D.V. Gansbeke \& W. Vyverman. 2005. Influence of changes in salinity and light intensity 
on growth of phytoplankton communities from the Schelde river and estuary (Belgium/The Netherlands). Hydrobiologia. 540:105-115.

Mizuno, T. 1970. Illustration of the Freshwater Plankton in Japan. Hoikusha Publishing Co. Ltd. Osaka, Japan. 351 p.

Odum, E.P. 1988. Fundamental of Ecology. Phidelphia: W.B. Sounders Company.

Ozbay, H. 2011. Composition and Abundance of Phytoplankton in Relation to Physical and Chemical Variables in The Kars River, Turkey. International Journal of Experimental Botany. 80: 85-92.

Palleyi S., Kar R.N \& Panda C.R. 2011. Influence of Water quality on the biodiversity of phytoplankton in Dhamra River Estuary of Odisha Coast, Bay of Bengal. J. Appl. Sci. Environ. Manage. Vol. 15 (1) 69 74.

Piehler M.F., L.J. Twomey, N.S. Hall, \& H.W. Paerl. 2004. Impact of Inorganic Nutrient Enrichment on Phytoplankton Community Structure and Function in Pamlico Sound, NC, USA. Estuarine, Coastal and Shelf Science. 61: 197-209.

Reynolds, C.S., J.G. Tundisi \& K. Hino. 1984. Observation on a Metalimnetic Phytoplankton Population in a Stably Stratified Tropical Lake. Arch. Hydrobyol. Argentina. 97: 7-17.

Ruttner, F. 1973. Fundamental of Limnology. Third Edition. University of Toronto Press. Toronto Canada. 117p.

Sabater, S. (1990). Phytoplankon composition in a medium-sized medditerranean river: The Ter (Spain). Limnetica 6: 47-56.

Steinhart,G S ; Likens,G E ; Soto,D (2002). Physiological indicators of nutrient deficiency in phytoplankton in southern Chilean lakes, Hydrobiologia, 489(1-3): 21-27.
Thornton, K.W., B.L. Kimmel \& F.E. Payne. 1990. Reservoir Limnology : Ecology Perspective. John Wiley \& Sons. Inc, New York. 246p. 